\title{
Effects of Socioeconomic Factors on Nigeria's Life Expectancy at Birth
}

\author{
Ilker Etikan*, Ogunjesa Babatope, Meliz Yuvalı and Savaş Ilgi \\ Department of Biostatistics, Near East University, Cyprus
}

*Corresponding author: İlker Etikan, Department of Biostatistics, Near East University, Faculty of Medicine, Nicosia-TRNC, Cyprus.

Received Date: March 04,2019

Published Date: March 08, 2019

\begin{abstract}
Life expectancy is considered as a veritable determinant of health outcome of various nations of the world. In a bid to improve the health condition of their citizenry, several governments in the world monitor their health policies and strategies using this indicator as an evaluation tool.This study considers the effects of socioeconomic factors such the percentage of Nigeria's government's health expenditure of the Gross Dometic Product (GDP), the percentage of the private health expenditure of the GDP , the percentage of people with access to safe water in the population, and the percentage of people with access to basic sanitation system on the life expectancy at birth. Using the multiple linear regression model, it found that Nigeria's government health expenditure of the Gross Dometic Product (GDP), and the percentage of the private health expenditure of the GDP at a significant level of $\alpha=0.05$ do not have a significant effect on the life expectancy, but however, access to safe water in the population and basic sanitation system do have a significant effect on the country's life expectancy at birth.
\end{abstract}

Keywords: Life expectancy at birth; Socioeconomic Factors; Health care benefits

\section{Introduction}

The distinct ripple effects brought about by globalization is clearly evident in the lifestyle of the 21st century human population, with more stint in the advanced nations of the world. The quest to help the population live more smarter owing to the application of social oriented technologies with health care benefits and sustainability of the environment are all considered leverages to achieving good standard living. In the context of the health industry, today's medical field is characterized by efficient and effective preventive and curative medical practices that tends to keep the human population healthy, thus improving the lifespan of human as a result of provision and unhindered access to essential social and basic amenities, minimization of health disparities in the population, improved work balance and sensitization on healthy nutritional benefits are all vital factors contributing to this goal. Before the advent of human economic development and growth, poverty, lack of basic amenities and diseases are noted to be the key deciminating scourges that ravage the human population and reduction of human life longevity. Raza et al., (2012) attributed many death occurrences before age 54 years in the 20th century to death from diseases, especially due to HIV/AIDS with sub-Saharan
Africa accounting for the greatest causality. In view of this, different government of countries in the world recognized the need to keep their population healthy and strong in a bid to improve productivity, especially among their working force and to ensure the reduction in disease burden which invariably optimize public spending and encourage economic prosperity. This led to the development of a metric called life expectancy to measure nations' performance index in prolonged longevity.

\section{What is Life Expectancy?}

According to the Organisation for Economic Co-operation and Development (OECD) with headquarter at France in a 2001 report on social indicator defined the life expectancy “...as the average number of years that a person could expect to live if he or she experienced the age-specific mortality rates prevalent in a given country in a particular year." Life expectancy has become a foremost indicator that has become a baseline measure through which many nations in the world evaluate their various health policies, strategies and interventions in line with what is obtainable in a global context. The Western nations, Oceania and their developed counterparts from Asia have since continued to dominate the chart 
of high top ranking countries with spectacular record as seen in the table below Table 1.

Table 1: Life Expectancy Trend [1].

\begin{tabular}{|c|c|c|c|c|c|}
\hline Region & $\mathbf{1 9 6 0 - 6 9}$ & $\mathbf{1 9 7 0 - 7 9}$ & $\mathbf{1 9 8 0 - 8 9}$ & $\mathbf{1 9 9 0 - 9 9}$ & $\mathbf{2 0 0 0 - 0 4}$ \\
\hline World & 52.5 & 58.1 & 61.4 & 63.7 & 65.4 \\
\hline $\begin{array}{c}\text { Sub- } \\
\text { Saharan } \\
\text { Africa }\end{array}$ & 42.4 & 46.3 & 49 & 47.6 & 45.9 \\
\hline Asia & 48.5 & 56.4 & 60.4 & 64 & 67.3 \\
\hline Europe & 69.6 & 71 & 72 & 72.6 & 73.7 \\
\hline $\begin{array}{c}\text { Latin } \\
\text { America \& } \\
\text { Caribbean }\end{array}$ & 56.8 & 60.9 & 64.9 & 68.3 & 71.5 \\
\hline $\begin{array}{c}\text { Northern } \\
\text { America }\end{array}$ & 70.1 & 71.6 & 74.3 & 75.5 & 77.6 \\
\hline Oceania & 63.7 & 65.8 & 69.3 & 71.5 & 74 \\
\hline
\end{tabular}

According to a World Health Organization (WHO) Global health observatory 2015 report, the average global life expectancy of the world population is 71.4 years. Japan, in the 2017 World Health Statistics has the highest life expectancy of 83.7 years closely followed by Switzerland 83.4 years while Sierra Leone and Angola have 50.1 and 52.4 years respectively and are the least ranked countries. The corresponding development that has characterized the developed and some developing countries in terms of technology breakthrough in biomedical research, environmental protection, improved earnings, quality spending in health and social care services cannot be said of most Sub- Saharan Africa, that is highly plagued with high mortality level, morbidity, illiteracy,dysfunctional health care system, unemployment and poverty among many other life threatening conditions. Nigeria, which is a case study of this research work is not exclusive of these conditions.

\section{Study Area}

Nigeria with the seat of power at Abuja is the most populous black nation in the world and located in the sub-Saharan region of the African continent, precisely the West Africa region. The eastern part of the country shared a boundary post with the Cameroonians while the North shared a boundary with the Republic of Chad and Niger. The Southern part of the country is encamped by the Atlantic ocean and the western part shares a boundary with the Republic of Benin [2,3]. The country has a population of 182 million inhabitants as indicated by the Nigeria Population Council in a 2017 press release (NPC,2017) [4]. Nigeria is made up of 36 states and the federal capital territory. Geographically divided into six geopolitical zones, namely the North West, North East, North, Central, South West, South East and South South, there are various factors that make each of these regions distinct ranging from ethnic diversities, languages, political power, economic prosperity, literacy, health disparities and urbanization. As a crude oil producing nation with other abundant natural resources, the country is considered the largest oil producing nation with a very huge deposit of natural liquefied gas in the Africa continent [5,6]. The crude oil production is about 2.7 million barrels per day and this accounts for about $90 \%$ of the country's export.
The crude oil is a major contributor to the country's Gross domestic Product(GDP), thus making it the country's main stay source of revenue. However, despite the huge wealth generated from the oil sector and other sources, about $70 \%$ of the population still live below the poverty line. The government revenue allocation to major sector of the country's economy, especially health and education still falls short of the United Nations(UN) recommendations. In their research, Obanla et al.,(2013) reported how poor funding has greatly affected the Nigeria healthcare industry.

\section{Nigeria Healthcare Sector}

Access to basic health care, according to the United Nations (UN) is one of the fundamental human right of an individual (Aniekwu, 2006). A nation's quality healthcare system not only increase economic prosperity, but also aid in the growth and sustainability of the country's giant stride developmental processes. A healthy nation makes healthy workers that propels every mechanisms required for economic progress and attainment of a high standard of living [7]. In Nigeria, both the private and the government play an active role in the health industry. However, the government controlled health services still dominate the industry. There are about 23640 health care institutions in the country, according to the Federal Ministry of Health report [8]. The public health care services are basically grouped into three categories, namely primary, secondary and tertiary which are each oversee by the three tiers of government [9]. The primary health care services are generally discharged by several primary health care centers and dispensary centers that spread across the nation,especially the rural areas. They are the first point of contact for most people seeking medical care services and they are coordinated by the local government authority where they are located. The secondary health care services such as the general hospitals and state hospitals do offer more specialized healthcare services such as gynecology, pediatrics consultations and so on and are primarily financed by the State government. On the other hand, the tertiary health care services which are provided by the Federal medical centers and teaching hospitals are the apex of all health care institutions in the country. These apex healthcare facilities provide more advance medic care to the populace and are under the direct control of the Federal government [10].

\section{Nigeria's Dysfunctional Health Care System}

The state of the nation's health care system has been a great concern to many stakeholders and think tank in the country and international agencies. Most especially relative to Nigeria continued low ranking in the life expectancy index. The current male's life expectancy is 53 years while their female counterpart is put at 56 years. On average, the life expectancy in the country is 54.5 years [11]. This ranking does not only fell short of the world's averages, but also falls below most African's countries that are not in the same caliber with the country in terms of resourcefulness and national wealth.

The problems of the country's healthcare industry are indeed multifaceted with corresponding adverse effect on the life 
expectancy of the inhabitants. A current trend that has always been identified with the country's comatose health care services are not short from problems such as inadequate funding, dearth of qualified health professionals, poor infrastructure provisions, weak public health oriented research, poor record keeping among many other factors that have created a dysfunctional system [12].

\section{Poor funding}

The poor funding of Nigeria health care industry is considered as one of the many woes responsible for its poor performance in meeting the health need of the country's teeming population [10]. This funding majorly comes from the federal government, donor agencies, out of pocket payment from patients, subsidies, health insurance schemes [13].The government budgetary allocation to the industry is below the expectation of what is required to reinvigorate and sustain the system. In a research conducted on public health financing in Nigeria, Uzochukwu et al. [14] reiterates the poor funding contributions as a major problem facing the country. The table below gives a synopsis of health care funding in the country (Table 2).

Table 2: Federal Government Health Expenditure [14].

\begin{tabular}{|c|c|c|c|c|c|}
\hline Year & $\begin{array}{c}\text { Total Allocation (NGN } \\
\text { Bilion) }\end{array}$ & $\begin{array}{c}\text { Allocation to Health } \\
\text { (NGN Billion) }\end{array}$ & $\begin{array}{c}\text { As Percentage of } \\
\text { Total Budget }\end{array}$ & GDP (NGN Billion) & As Percentage of GDP \\
\hline 2009 & 3557.7 & 154.6 & 4.3 & $25,102.44$ & 0.6 \\
\hline 2010 & 4427.2 & 164.9 & 3.7 & $30,980.84$ & 0.5 \\
\hline 2011 & 4971.9 & 266.7 & 5.4 & $36,123.11$ & 0.7 \\
\hline 2012 & 4877.2 & 282.8 & 5.8 & $42,132.16$ & 0.7 \\
\hline 2013 & 4920 & 279.2 & 5.7 & $63,5.4 .00$ & 0.4 \\
\hline
\end{tabular}

In a World Health Organization (WHO) 2017 health statistics publication reported that the country's public spending on vital social services such as education, health and other forms of social protection measures stands at $8.2 \%$ of the total budgetary allocation which made Nigeria occupied the 33rd position out of the 47 countries ranked in Africa [15].

\section{Availability of health care professionals}

The WHO skilled professional density, which is a measure of a healthcare worker for every 10,000 people in Nigeria is 18.3 [15] compared to her economy rival; South Africa with a 58.8 record. Adebayo et al. [16] in study conducted on Nigeria's healthcare workforce lamented the availability of healthcare professional in the country. Annually,various tertiary institutions and special medical training schools in the country produced qualified healthcare professionals, but with a greater percentage lost in the wave of brain drain to most western worlds and other developed countries that have profound remuneration packages and better working condition. For instance, about 8000 medical professionals from Nigeria work in the United States of America while just about 35,000 of them currently attends to the over 180 million of the Nigeria populations [17]. The remaining few are often overworked, poorly paid and left to work with crude and obsolete medical devices and techniques that are in contrast with the technological advancement the medical field have experienced over the years.

Poverty: Poverty is one of the greatest risk factor to the low life expectancy record of the nation. With over $70 \%$ of the population living below the poverty line as earlier stated, the quest for medical treatment after sickness is not often prioritized, as the meager household income is barely sufficient to cater for feeding. This is far worse in rural communities where medical attention is the very last resort for many people usually only after all traditional means of treatment have been exhausted. As a result of poverty, many children become more malnourished resulting into death incidences before age 5 years and the maternal health is equally at grave risk, with many dying during child delivery as a result of conditions stemming from poor nutrition.

Access to clean water and proper sanitation: An important component of the United Nations (UNs) sustainable goals for the developing countries is to ensure access to clean water.This is owing to the fact that the risk of morbidity and mortality of the human population gets drastically reduced provided the people have access to safe and clean water (Clasen et al.,2007). Clean water provision is a major problem in the third world countries. About 1.8 million people are reported to die annually as a result of waterborne diseases such as diarrhea attributable to the consumption of unsafe water and its food contents [11].

Nigeria is not a stranger to this water problem.The prevalence and incidence of disease such as cholera, typhoid, hepatitis, which are waterborne diseases are common recurrent public health issues in the country. Unsafe water sources are hotbeds for many pathogens and several other disease vectors that are detrimental to human health through a direct contact or indirect contact by consumption of seafoods that serve as hosts to these organisms [18]. The table below gives an overview of water borne disease prevalence in sub-Saharan Africa (Table 3).

Table 3: Water Borne Diseases prominent in sub-Saharan Africa [18].

\begin{tabular}{|c|c|c|c|}
\hline \multirow{4}{*}{ Group } & Disease & Route leaving host & Route of Infection \\
\hline \multirow{3}{*}{ Disease which are often water-borne } & cholera & Faeces & Oral \\
\cline { 2 - 4 } & typhoid & Faeces/urine & Oral \\
\cline { 2 - 4 } & infectious hepatitis & Faeces & Oral \\
\hline
\end{tabular}




\begin{tabular}{|c|c|c|c|}
\hline & Giardiasis & Faeces & Oral \\
\hline & Amoebiasis & Faeces & Oral \\
\hline & Dracunculiasis & Cutaneous & Oral \\
\hline \multirow{10}{*}{$\begin{array}{l}\text { Disease which are often associated } \\
\text { with poor hygiene }\end{array}$} & bacillary dysentery & Faeces & Oral \\
\hline & Enteroviral diarrhea & Faeces & Oral \\
\hline & Paratyphoid fever & Faeces & Oral \\
\hline & Pinworm (Enterobius) & Anal & Oral \\
\hline & Amoebiasis & Faeces & Oral \\
\hline & Scabies & Cutaneous & Cutaneous \\
\hline & Skin sepsis & Cutaneous & Cutaneous \\
\hline & Lice and typhus & Bite & Bite \\
\hline & Trachoma & Cutaneous & Cutaneous \\
\hline & Conjunctivitis & Cutaneous & Cutaneous \\
\hline \multirow{3}{*}{$\begin{array}{l}\text { Diseases which are often related to } \\
\text { inadequate sanitation }\end{array}$} & Ascariasis & Faecal & Oral \\
\hline & Trichuriasis & Faecal & Oral \\
\hline & $\begin{array}{l}\text { Hookworm (Anclyclostoma/ } \\
\text { Necator) }\end{array}$ & Faecal & Oral/percutaneous \\
\hline $\begin{array}{l}\text { Diseases with part of life cycle of } \\
\text { parasite in water }\end{array}$ & Schistomiasis & Urine/faeces & Percutaneous \\
\hline $\begin{array}{l}\text { Diseases with vectors passing part of } \\
\text { their life cycle in water }\end{array}$ & Dracunculiasis & Cutaneous & Oral \\
\hline
\end{tabular}

This situation gets worsened when consider the various flawed refuse dumping processes of both human and industrial waste into the water sources which doubles as source used for drinking,cooking and other domestic usage. The WaterAid organisation; a global safe water campaigner in their annual 2016 reported that about 71 percent of the Nigeria population is without access to hygienic toilet facilities while about $25 \%$ of the population make a practice of passing human solid waste in the open. The country ranked third coming close after India and China in open defecation practice [19]. The aftermath effect of these poor sanitation results in many of these waste getting washed into the waters used by various community dwellers.

In the context of this research, we will seek to evaluate the effect of funding, access to safe drinking water and proper sanitation practices on Nigeria's life expectancy record.

\section{Methodology}

The multiple regression method will be adopted in this research study to build the relational model of the variables under study. The data variables used for this study are under the period of year 2000 to year 2015 and they are obtained from the databases of the World Health Organisation (WHO), Index Mindu and World Bank [20] .The variables include the Nigeria's life expectancy (LIFEX) value, the percentage of Nigeria's government public health expenditure (PEXP) of the Gross Dometic Product (GDP), the percentage of the private health expenditure (PVEXP) of the GDP , the percentage of people with access to safe water in the population (ASW), and the percentage of people with access to basic sanitation services (PBS).

\section{Multiple Regression Model}

This is an inferential statistical model widely used in predictive analysis. It is used to evaluate the relationship between a response variable and more than two explanatory variables. Alternatively, the response variable is called dependent variable and the explanatory variables are called independent variables [21]. The model is estimated based on the least square criterion which seek to find the best fit line in the data plot by minimizing the sums of squares of the errors which is the difference between the actual and observed values.

Mathematically, a multiple regression model can be stated as:

$Y=\beta 0+\beta 1 X 1+\beta 2 X 2+\beta 3 X 3+\ldots \ldots .+\beta N X N+\varepsilon$

From the above equation, the $\mathrm{Y}$ is the dependent variable and the $\beta 0 \ldots . . . \beta \mathrm{N}$ are called the regression coefficients and their values are estimated from the data under consideration while the $\varepsilon$ (epsilon) is called the error term or residual error. The error term is used in testing the final significance of the model using the Fishers's distribution table and the significant test for each of the independent variables make use of the t-distribution table. The error term is expected to be independently distributed as well as follows a normal distribution pattern before result outputs can be considered valid. Due to advancement in statistical computation, the use of statistical softwares is generally made available to conduct these tests rather than the classical manual computational methodology.

In this study, the dependent variable $(\mathrm{Y})$ is the life expectancy (LIFEX) value while the independent variables are the percentage of Nigeria's government's health expenditure (PEXP) of the Gross Dometic Product (GDP), the percentage of the private health expenditure (PVEXP) of the GDP , the percentage of people with access to safe water in the population (ASW), and the percentage of people with access to basic sanitation system (PBS).

LIFEX = f(PEXP, PVEXP, ASW, PBS ) 
The model can therefore be re-written as shown below:

LIFEX $=\beta 0+\beta 1$ PEXP $+\beta 2$ PVEXP $+\beta 3$ ASW $+\beta 4$ PBS

The computation of this model will be done using the IBM SPSS version 20

Table 4: Regression Model Summary.

\begin{tabular}{|c|c|c|c|c|}
\hline \multicolumn{5}{|c|}{ Model Summary $^{\mathbf{b}}$} \\
\hline Model & $\mathrm{R}$ & R Square & Adjusted R Square & Std. Error of the Estimate \\
\hline 1 & $.999 \mathrm{a}$ & 0.998 & 0.998 & 0.10938 \\
\hline
\end{tabular}

a.

Predictors: (Constant), PBS, PEXP, PVEXP, ASW

b. Dependent Variable: LIFEX

Table 5: The ANOVA Table.

\begin{tabular}{|c|c|c|c|c|c|c|}
\hline \multicolumn{7}{|c|}{ ANOVAa } \\
\hline Model & \multicolumn{2}{|c|}{ Sum of Squares } & df & Mean Square & $\mathbf{F}$ & Sig. \\
\hline \multirow{2}{*}{1} & Regression & 72.402 & 4 & 18.1 & 1512.941 & $.000 \mathrm{~b}$ \\
\hline & Residual & 0.132 & 11 & 0.012 & & \\
\hline
\end{tabular}

a.

Predictors: (Constant), PBS, PEXP, PVEXP, ASW

b. Dependent Variable: LIFEX

Table 6: Predictors' Coefficients.

\begin{tabular}{|c|c|c|c|c|c|c|c|}
\hline \multicolumn{7}{|c|}{ Coefficients $^{\mathrm{a}}$} & \multicolumn{2}{|c|}{ Sig. } & \multicolumn{2}{c|}{$\mathbf{9 5 . 0 \%}$ Confidence Interval for B } \\
\hline Model & Unstandardized Coefficients & Standardized Coefficients & $\mathbf{t}$ & & & Lower Bound & Upper Bound \\
\hline & B & Std. Error & Beta & -1.414 & 0.185 & -105.395 & 22.933 \\
\hline (Constant) & -41.231 & 29.152 & - & 1.412 & 0.186 & -0.12 & 0.551 \\
\hline PEXP & 0.215 & 0.153 & 0.023 & -2.082 & 0.061 & -0.399 & 0.011 \\
\hline PVEXP & -0.194 & 0.093 & -0.034 & 2.519 & 0.029 & 0.207 & 3.067 \\
\hline ASW & 1.637 & 0.65 & 0.913 & 5.329 & 0 & 0.366 & 0.881 \\
\hline PBS & 0.624 & 0.117 & 1.918 & & & \\
\hline
\end{tabular}

a. Dependent Variable: LIFEX

The table above indicates that the overall $p$ - value of the regression model is 0.000 which is lesser than the significance level of $\alpha=0.05$.Thus, since the P-value is lesser than the significance level of $\alpha=0.05$, it can be concluded that the regression equation model is significant and the model adequately predicts the dependent variable which is the life expectancy indicator (Table 6).

The above table gives the individual coefficient values of the independent variables included in the model. The PEXP and the PVEXP variables have indicated no significant effects on the regression equation since their respective P-values of 0.186 and 0.061 are greater than the significance level of $\alpha=0.05$. However, the ASW and the PBS variables are significant since their respective P-values of 0.029 and 0.000 are lower than the significance level of $\alpha=0.05$.

The final regression model can therefore be stated as :

LIFEX $=-41.231+1.637 \mathrm{ASW}+0.624$ PBS

\section{Conclusion}

Life expectancy is a world wide acceptable indicator to assess the healthiness level of a country, hence government considers this indicator as a guide to evaluate their approaches and strategies to guarantee healthy lifestyle in the populace. In order to achieve a

\section{Result Presentation}

The model summary table shows that R-Square value is $99.8 \%$. This shows that $99.8 \%$ variability in the life expectancy record is explained by the regression equation model (Table $4 \& 5$ ). 


\section{References}

1. Adetunji J, Bos ER (2006) Levels and Trends in Mortality in Sub-Saharan Africa: An Overview. In: Jamison DT, Feachem RG, Makgoba MW, et al. (Eds.), Disease and Mortality in Sub-Saharan Africa ( $2^{\text {nd }}$ edn), The International Bank for Reconstruction and Development, Washington (DC), USA

2. Akpan Ebe IN (2017) Reforestation in Nigeria: History, current practice and future perspectives. Reforesta 3: 105-115.

3. Douglas A, Phillips (2004) Nigeria (Philadelphia: Chelsea House Publisher): p. 10. Also see Achebe, Chinua (2000),"Home and Exile", Oxford University Press, New York, USA

4. NPC (2017) nigeria's population now 182 million.

5. Akinlo Anthony Enisan (2012) How Important is Oil in Nigeria's Economic Growth? Journal of Sustainable Development. 5(4): 165-179.

6. Odularu Gbadebo Olusegun (2008) Crude Oil and the Nigerian Economic Performance. Oil and Gas Business.

7. Eneji Mathias Agri, Dickson Vonke Juliana, John Onabe Bisong (2013) Health care expenditure, health status and national productivity in Nigeria (1999-2012). Journal of Economics and International Finance 5(7): 258-272.

8. Ugo O, Ezinne EA, Modupe O, Nicole S, Winifred E, et al. (2016) Improving Quality of Care in Primary HealthCare Facilities in Rural Nigeria: Successes and Challenges. Health Services Research and Managerial Epidemiology: 3.

9. Onotai Lucky O, Nwankwo NC (2012) A review of the Nigerian health care funding system and how it compares to that of South Africa, Europe and America. Journal of Medicine and Medical Sciences 3(4): 226-231.

10. Yunusa U, Irinoye O, Suberu A, Garba AM, Timothy Gd, Dalhatu A, Ahmed Sf (2014) Trends and Challenges of Public Health Care Financing System in Nigeria: The Way Forward. Journal of Economics and Finance 4(3): 28-34.

11. World Health Organization (2005) Life expectancy increased by 5 years since 2000, but health inequalities persist.

12. Kress Daniel H, Yanfang Su, Hong Wang (2016) Assessment of Primary Health Care System Performance in Nigeria: Using the Primary Health Care Performance Indicator Conceptual Framework. Journal Health
Systems \& Reform 2(4) Special Issue on the Nigerian Health System: 302-318.

13. Olakunde BO (2012) Public health care financing in Nigeria. Which way forward? Annals of Nigeria Medicine 6(1): 4-10.

14. Uzochukwu BSC, Ughasoro MD, Etiaba E, Okwuosa C, Envuladu E, et al. (2015) Health care financing in Nigeria: Implications for achieving universal health coverage. Nigerian journal of Clinical Practice 18(4): 437-444.

15. World Health Organisation (2017) World Health Statistics.

16. Adebayo Oladimeji, Labiran Adetunji, Emerenini Chime Franklin, Omoruyi Leslie (2016) Health Workforce for 2016-2030: Will Nigeria have enough? International Journal of Innovative Healthcare Research 4(1): 09-16.

17. Ighobor Kingsley (2016) Diagnosing Africa's medical brain drain. Africa Renewal.

18. Nwabor Ozioma Forstinus, Nnamonu Emmanuel Ikechukwu, Martins Paul Emenike, Ani Ogonna Christiana (2015) Water and Waterborne Diseases: A Review. International Journal of TROPICAL DISEASE \& Health 12(4): 1-14

19. WaterAid (2016) World Toilet Day 2016: Nigeria's sanitation crisis.

20. World Bank (Online) Nigeria Life expectancy at birth.

21. Brauna MR, Altan H, SBM Beck (2014) Using regression analysis to predict the future energy consumption of a supermarket in the UK. Applied Energy 130(1): 305-313.

22. Lu J, Yuan F (2005) The effect of drinking water quality on the health and longevity of people-A case study in Mayang, Hunan Province, China. IOP Conf. Series: Earth and Environmental Science 82 (2017): 012005.

23. Gulis, G (2000) Life expectancy as an indicator of environmental health. European Journal of Epidemiology 16(2): 161-165.

24. Keita M (2014) Standards of living and health status: the socioeconomic determinants of life expectancy gain in sub-Saharan Africa, MPRA: 57553.

25. Index Mundi (Online) Nigeria Health Statistics.

26. OECD (2009) Health at a Glance 2010: OECD Indicators, OECD Publishing, Paris, France. 